Revista de la red interuniversitaria de estudios sobre las literaturas rioplatenses contemporáneas en Francia

$20 \mid 2019$

Situación

\title{
Formas de narrar lo contemporáneo: intimidad, repetición, adicción
}

Ways of narrating the contemporary: intimacy, repetition, addiction

Les modes de narration du contemporain : l'intimité, la répétition, l'addiction

\section{Lucía Caminada Rossetti}

\section{(2) OpenEdition}

\section{Journals}

Electronic version

URL: http://journals.openedition.org/lirico/8414

DOI: $10.4000 /$ lirico.8414

ISSN: 2262-8339

\section{Publisher}

Réseau interuniversitaire d'étude des littératures contemporaines du Río de la Plata

Electronic reference

Lucía Caminada Rossetti, « Formas de narrar lo contemporáneo: intimidad, repetición, adicción », Cuadernos LIRICO [En línea], 20 | 2019, Publicado el 10 julio 2019, consultado el 02 junio 2020. URL http://journals.openedition.org/lirico/8414 ; DOI : https://doi.org/10.4000/lirico.8414

This text was automatically generated on 2 June 2020 .

\section{(c) $($ ) $\odot$ (S)}

Cuadernos LIRICO está distribuido bajo una Licencia Creative Commons Atribución-NoComercial-

SinDerivar 4.0 Internacional. 


\title{
Formas de narrar lo contemporáneo: intimidad, repetición, adicción
}

\author{
Ways of narrating the contemporary: intimacy, repetition, addiction \\ Les modes de narration du contemporain : l'intimité, la répétition, l'addiction
}

\author{
Lucía Caminada Rossetti
}

1 En este artículo se abarca un tramo de la literatura rioplatense contemporánea a partir de un doble proceso: cómo se escribe y se lee desde el presente (Laddaga 2007). En este sentido, la relación entre lo contemporáneo y el presente en la literatura se explora a partir de la politización del tiempo y de "intentar visualizar aquello que se concibe como tránsito, esto es, el tiempo" (Montaldo 2017: 113). En esta ebullición, gestación y transición es donde ubico un recorrido por las obras de María Moreno Black out que se publicó en el 2016, El pasado de Alan Pauls del 2004 y La novela luminosa de Mario Levrero del 2005.

2 Al intentar trazar ciertas líneas de las políticas temporales y espaciales que conforman estos discursos que bosquejan subjetividades contemporáneas, identifico algunos aspectos compartidos en los textos: 1) son extensos (inmensos), largos y densos; 2) las escrituras de la intimidad se instalan en primer plano, en la complejidad del giro autobiográfico (Giordano, 2008) aunque funcionando diversamente en cada obra de acuerdo con el estatuto del sujeto de enunciación: los límites borrosos del yo autobiográfico en La novela luminosa y en Black out, y la voz que construye a Rímini que es el protagonista de $E l$ pasado y lente para ver todo el funcionamiento de la novela-, que narra desde la experiencia vivida; 3) la dificultad de establecer un pacto de lectura con las leyes de determinado género a la hora de identificarlo funcionando en el entramado textual (diario de escritor, novela autobiográfica, texto confesional, autoficción particular, "novela viva", testimonio, etc.); 4) la intimidad se va configurando en torno a determinada adicción que como fenómeno se encuentra estrechamente ligado al exceso que produce la práctica de escritura, el desenfreno de dar vueltas en torno a la palabra y lo extremo como parte funcional del aparato 
creativo; 5) el proceso de escritura, y por ende, el texto, resulta inacabado, vuelve sobre sí mismo, sigue en proceso constante, tornándose particularmente condensado y repetitivo; 6) el acervo de lecturas de y sobre literatura de diverso género está presente en todas las voces que cargan con el peso de las referencias literarias que provocan de alguna manera el deseo de escritura.

3 Ahora bien, si esto se presenta en las obras: ¿a qué lectores se interpela en esta contemporaneidad? Dos cuestiones se imponen al respecto: el género literario, con sus formas complejas y heterogéneas de manifestarse y el estatuto del sujeto de enunciación. En este sentido, Reinaldo Laddaga argumenta que en algunos textos contemporáneos más allá de que se hibridiza la voz narrativa (en las formas de hablar de sí mismo) y el género (entre biografía, nota, diario, novela, apunte, etc.) cambia la forma de dirigirse al lector:

Un escritor habla en nombre propio, pero sin realizar las clases de diferenciaciones que eran comunes: un escritor habla en nombre propio, describe la circunstancia en la que se encuentra y las cosas que piensa de esa circunstancia, en el mismo lugar, la misma página o el mismo libro, en que despliega fabulaciones a veces extremas, de modo que a nosotros, sus lectores, podría parecernos que no distingue entre una cosa y otra. Esta manera se ha vuelto tan normal que tal vez no nos demos cuenta de cuán extraña es su reiterada presencia (2007: 29).

Estas fabulaciones extremas de las cuales habla Laddaga, imperceptibles para el lector, nos lleva a repasar por qué estamos allí leyendo esas confesiones, anotaciones, proyectos, notas, entretelón psicológico de voces que narran "la circunstancia en la que se encuentra y las cosas que piensa de esa circunstancia". Lo que está expuesto en cada libro, en estos casos, es la centralidad de una subjetividad narrada en el tránsito entre lo íntimo, lo adictivo y la repetición.

¿De donde surge el exceso y cómo se vincula con aquello extremo ${ }^{1}$ ? Lo extremo y lo contemporáneo parecen estar atrapados por la misma vorágine cultural, en un cubículo espacial donde solo cabe un individuo. Cuerpos que escriben y se desbordan. Cuerpos irreverentes embebidos en adicciones, en algo: la droga, el alcohol, la computadora. Cuerpos disciplinados por la escritura: traducir, escribir, anotar, idear itinerarios de literatura y lecturas.

Los textos encierran, por lo tanto, según mi hipótesis, un doble movimiento del discurso y una ritmicidad: la repetición, como ritmo del discurso, como una vuelta permanente al centro de la obra que recomienza desde un punto que acecha la temporalidad y de allí se piensa la fragmentación y la fluidez; el movimiento de lo íntimo que configura la espacialidad, que pone al sujeto de enunciación en el centro de la obra: su vida, su cotidianeidad, su funcionamiento orgánico, la corporalidad, el sentir fisiológico, etc.; por último, el movimiento de la adicción, que hace del discurso que marca la acción que se repite, moviendo no tanto la historia como la escritura.

\section{Movimiento. Espacio e intimidad}

7 Antes que nada, es necesario precisar el estatuto del sujeto de enunciación diferente en cada texto: se reconoce una escritura yoica en Moreno y en Levrero, por ejemplo; asimismo, Rímini es el centro de la novela de Pauls, un protagonista del cual como lectores no podemos escapar, ni de sus relaciones, ni de su cuerpo, ese yo agónico del narrador atrapado por los movimientos orgánicos del personaje. Esta estatuto ambiguo, 
por una parte, tiene que ver con la imprecisión de los géneros y como resultado de esto, la secuela recae sobre las escrituras del yo, los pactos de lectura y sus vínculos con el giro autobiográfico (Giordano 2007 y 2017). Lo que circunda estas voces envuelve, en el movimiento de los discursos, al espacio de la intimidad. En este sentido,

[...] lo íntimo tiene que ver con la manifestación de una distancia indecible que impide tanto identificarse, apropiarse sin restos de uno mismo, como ser identificado; una distancia que fuerza la enunciación, hace hablar o escribir, y transforma secretamente cualquier performance autobiográfica en una experiencia de la propia extrañeza. Lo íntimo no sería entonces, como se acostumbra pensarlo, una sutil gradación de lo privado, sino una dimensión irrepresentable de la subjetividad, una reserva de indeterminación que escapa a la dialéctica simple en la que lo privado y lo público se oponen para poder complementarse (Giordano 2017: 705).

8 Hay varias cuestiones claves en esta reflexión: la distancia indecible que construye espacios y lo irrepresentable de la subjetividad. Si hay una relación entre la representación, la subjetividad y la intimidad en estas obras, se vincula con la ficcionalización y estetización de la vida cotidiana, allí donde en la construcción del espacio de escritura se busca la experiencia auténtica.

9 En relación con esto, es importante notar que la definición de literatura expandida que propone Pauls, explora los intersticios entre arte y vida, entre el proceso creativo y lo cotidiano que envuelve ese proceder, es decir "con las diversas formas y los diversos géneros que practica una escritura incesantemente recorrida por inserciones autofigurativas" (Orecchia 2013). El antecedente de El pasado, de alguna manera, es la novela Wasabi, que traspola los extremos del yo y del tiempo, de la densidad y de la fragmentación en la escritura.

10 Pauls argumenta que la literatura expandida refiere básicamente a la trascendencia literaria que radica en sus puntos de conexión con el arte y la vida o como un acercamiento de la escritura a la performance. En este sentido, la densidad en el trabajo del lenguaje, en los tiempos reiterados, por ejemplo, hacen pensar que la novela de Pauls por su secuencia lógica, se inscribe más bien en una tradición narrativa de la novela, que en otra de experimentación con lo visual. En El pasado, literatura y vida se bifurcan, toman dos caminos diversos; en este sentido, Julio Premat se refiere a Pauls como un escritor que reivindica la literatura alternativa (2018: 85).

11 La construcción de lo íntimo, en este caso, gira en torno a la figura de Rímini. Desde ese personaje, se monta la ruptura con su pareja de años, Sofía, y las transiciones por los vestigios del pasado, nuevas aventuras y sus traducciones.

12 Por otra parte, La novela luminosa de Levrero se compone de tres partes: un extenso prólogo de un diario en el cual quedan registrados los monótonos días del narrador becado por Guggenheim que escribe notas de la potencial novela; de "La novela luminosa" y de un epílogo al diario. Si partimos de la base de que la obra de Levrero funciona como diario de escritor, el "registro de lo privado y lo público aparece iluminado, de tanto en tanto, por una reflexion sobre las condiciones y las (im)posibilidades del encuentro entre notación y vida, una reflexión que el diarista sitúa desde un punto de vista literario" (Giordano 2017: 709) y se va redactando mediante notas que él rechaza como literatura, es decir, que escribir no precisamente implica un resultado creativo o productivo en esta lógica ${ }^{2}$. Otro rasgo que caracteriza al escritor-diarista, continúa definiendo Giordano, es el conflicto que se plantea entre obra y diario. La obra funciona aglomerando las estructuras, como un diario de escritor: 
Los diarios de escritor exploran las condiciones de (im)posibilidad del encuentro entre notación y vida y exponen reflexivamente un saber de los vínculos entre escritura y experiencia, a través de digresiones sobre el sentido y las funciones de llevar un diario cuando también se escribe literatura (Giordano 2017, 703-704).

Entre notación y vida, el epílogo del diario comienza afirmando que "Un diario no es una novela". Desde esta lectura, la repetición en Levrero tiene la forma de un borrador, de una anotación "porque la única forma de estar seguro de un procedimiento, especialmente cuando está ligado al tiempo, es probarlo y probarlo y probarlo, y aun así..." (93). Y aun así, Levrero se asigna temporalmente períodos de centrifugación y de centripetación que se corresponderían con el encierro y con los momentos que se tiene más empatía con Chl o con el mundo externo en general, igualmente en cada contacto de introspección "cada una de estas sesiones conmigo mismo me deja agotado..." (140). A pesar de que aun en la página cuatrocientos esto demuestra que el desborde da cabida a una escritura imparable, la palabra se enreda en el enjambre de la estructura:

[...] estoy cansado de mí mismo, de mi incapacidad de vivir, de mi fracaso. No he logrado cumplir el proyecto de la beca; estuvo mal pensado, es inviable, no me di cuenta de que el tiempo no vuelve atrás, ni de que yo soy otro. Tengo pegado a la piel este rol de escritor, pero ya no soy un escritor, nunca quise serlo, no tengo ganas de escribir, ya he dicho todo lo que quería, y escribir dejó de divertirme y de darme una identidad (431)

Yo soy otro y la literatura ya no puede darme identidad. En esta forma irrecuperable del tiempo, Julio Premat alude a la imagen de la puerta como el texto del futuro en Levrero, como la postergación de la escritura que operan como "documentos como relatos e informaciones" funcionando como la preparación de la novela (2016). En esta misma línea de interpretación, la escritura procede como un "gesto póstumo, como algo que sobrevive, escribir tarde, escribir después" (Astutti).

El texto de María Moreno es el último en publicarse de la trilogía elegida. Lo que se retoma en esta obra desde su misma estructura, es este doble movimiento y ritmo del discurso que se teje entre escritura del yo (retrato), la revisión literaria (el microensayo) y el alcohol (el territorio de lo íntimo). En tanto testimonio ${ }^{3}$ la obra funciona como "la descripción de una lucha salvaje cuya verdad más íntima -la que se recibe en el cuerpo y se arrastra siempre en la escritura-, después de todo, quizá esté expuesta" (Crespi 2017a: 6). El tono confesional y el giro autobiográfico se identifican en un despliegue de saberes de lo íntimo, ya que "toda su obra es, de un modo u otro, autobiográfica" (Giordano 2008: 55). Por eso subraya Moreno: "Si escribo lo que escribo, ¿me desnudo? Hay quienes leen como si se tratara de la vida misma" (2016: 271) Con la vida misma ¿se refiere a la experiencia de lo vivido? ¿Cómo narrar la postexperiencia?

Al final del libro, en una hoja aparte, Moreno argumenta que esta suerte de novela viva se escribe como "tributo múltiple y ritual de despedida sin ningún resquicio para la nostalgia -sólo se tiene nostalgia de lo que no se ha vivido-" (407). Es decir, que es a partir de la experiencia vivida, donde la escritura se constituye de algún modo como proyecto y como potencial objeto literario. Esta preexistencia de la obra dada en lo experimentado, se precede por la justificación de la circularidad de Black out.

17 La separación secuencial de la estructura es parte de una fundamentación que Moreno coloca al final en un apartado. Me pregunto si se podría objetar que la sección de microensayos funcione realmente como tal o que el retrato está allí operando (y por sobre todo entender de quién). 


\section{Ritmo. Tiempo y repetición}

18 El movimiento del discurso en su repetición implica pensar aquí en la fluidez del acto de narrar y a su vez en la fragmentación como parte de ese retorno productivo. Al partir de esta base, hablar del presente y de lo contemporáneo no excluye la repetición. Habrá siempre en ese presente de lectura una mirada hacia atrás y un proyecto que al menos sueñe con imaginar un futuro. Pero la encrucijada de la escritura contemporánea no puede prometernos que hoy será un momento de conclusión. Legados, tradiciones, historia(s), rupturas, ya nada nos podría sorprender cuando intentamos poner en el centro de la cuestión el proceso de escritura.

De hecho, respecto a la temporalidad y lo contemporáneo, Julio Premat en Non nova sede, afirma que hay un conflicto instalado que es el de la mirada sobre el presente y piensa que: "El pasado tiende a ser una innovación y una respuesta a los interrogantes del presente: el pasado como lo desconocido que vuelve y se redefine, como lo idéntico" (2018: 26). ¿Cómo pensar el tiempo y la narración a partir de la repetición? en este carácter transitorio del presente que a su vez evoca el retorno. A raíz de esto, se esboza el planteo ligado con el tiempo y el ritmo del discurso: el de Gilles Deleuze y su formulación de la repetición y la diferencia.

Deleuze propone que repetir se relaciona, antes que nada, con la diferencia. Es decir, en el lazo entre repetir y acción, se trata de lo que no es único ni igual "repetir es comportarse pero con respecto a algo único o singular que no tiene algo semejante o equivalente" (2002: 21). En este sentido, en cuanto al paso freudiano que da Deleuze para llegar a su propia definición indisociable al de diferencia (trazando previamente un mapa por los nódulos de la filosofía que rozan con este aspecto), se repite porque se reprime (43) y a su vez la repetición es transgresión (23). ¿Por qué se repite en las obras? También por que no se puede renunciar al goce. Y como hay goce, hay postergación. Respecto a la postergación de la escritura plantea Premat:

Escribir una historia que no solo avanza sino que también retrocede, cambia de rumbo y sin embargo, retoma, de alguna manera, las líneas abiertas en direcciones opuestas es postular una narración que se opone al tiempo lineal, a la cronología ineluctable, a la versión equívoca (2016).

21 Para ser más claros: en los textos, lo notable es por excelencia el eterno retorno al mismo punto que luego recomienza y vuelve a arrancar y torna sobre el mismo eje, lo rearma, lo desplaza, da vueltas y el cierre no tiene un punto final, es decir, la obra como producto inacabado y como unidad fragmentada, como estética procesada hecha de restos.

La cuestión de la repetición en la redacción de sus pasatiempos día a día, puede interpretarse con un gesto involuntario que asimismo va perfilando la producción repetitiva, hasta casi mecánica: "Puedo escribir lo que se me antoje; nadie me molesta, nadie me interrumpe, tengo todos los elementos y toda la comodidad que necesito, pero simplemente no tengo ganas, no quiero" (Levrero: 434). La adicción se presenta casi como un acto incompatible con la creación: es la productividad literaria contra el ocio de la máquina. La máquina creativa existe tan solo en ese enorme prólogo en forma de Diario que se prolonga en el bosquejo de la novela.

23 La fragmentación del tiempo está presente en la percepción, en la construcción de la memoria, en la ausencia de lo persistente. La forma imprecisa temporal, se acompaña por un espacio vacío y borroso, de experiencias vividas y recuerdos posibles. 
Levrero es un escritor que se posiciona en el umbral de un texto futuro dice Julio Premat y en esta dirección es que la escritura "puede ilustrar una obsesión contemporánea con el inicio, la exposición de los mecanismos de escritura, lo inacabado, la intimidad de la creación y los terrores ante un tiempo incomprensible". Levrero nunca termina de cerrar el proyecto, ni de prologarlo, ni de diferenciar el epílogo. Borrador, notita, apunte ${ }^{4}$, la novela en tanto dossier genético se traduce en "el intento de plasmar el instante, la cadencia de fechas, los tanteos ante el umbral de lo ideal: ése es el proyecto, tal cual se lo percibe al terminar la lectura" (2016).

En su vínculo con la adicción y la repetición, es notable identificar esta imposibilidad de la escritura con una práctica compulsiva de la anotación (acto de repetición) y del recomenzar luego de una "larga inmersión por sus horas frente a la computadora" añade que: "Ahora estoy embarcado en esta ofensiva contra mi adicción a la computadora. Mi teoría es que, si consigo irme deshabituando, iré recuperando algunas facultades y sobre todo tiempo de vigilia, quiero decir de vigilia útil, en horarios donde pueda compartirla con otra gente" (162).

2 En Black out "el desenfreno es una negociación" (403), es decir, que la continuidad o el ritmo del discurso se acompaña de una repetición pero en este caso, enredada con la adicción. No hay escritura sin alcohol. Como una suerte de combustible creativo, el alcohol funciona en el proceso escritural, va trazando los movimientos gráficos, los impulsos de la memoria, las tareas de estudiar la literatura. Cuerpo y texto: el cuerpo que se pone en la escritura, el cuerpo roto, borracho, hemorrágico que asimismo produce teoría, que escribe la tradición literaria contemporánea a partir de la crítica (Guebel, Pauls, Lamborghini, Aira, Levrero, etc etc.): "Hay linajes literarios por roce con una experiencia intensa que permite vivir por delegación mientras que quienes han escrito haberla vivido son proyectados como mártires" (272).

2 En Black out, el fluir de la escritura también dialoga con la repetición; en una parte de "El otro lado de la puerta vaivén", al igual que el prólogo a La novela luminosa, se narran en forma de diario treinta y cinco días del 5 de noviembre al 10 de diciembre en los cuales "escribir cada noche acompañaba una desesperación hasta entonces desconocida" (247). En este caso, Moreno realza el límite que existe en el discurso que en este caso, se expande en la libertada alcohólica del pulso de la historia que se cuenta: "Cuando bebo, de la boca a la mano y de la mano a la boca, yo no hago más que ejercer mi libertad y no estoy dispuesta a aceptar ser un caso clínico" (353).

Moreno pone en evidencia en los microensayos, algunas reflexiones que venimos cartografiando aquí, como la de literatura expandida de Pauls y lo que denomina como una "poética de farmacia" refiriéndose a la obra de Levrero. El concepto de literatura expandida, según ella, "lo procesa todo: sexualidad, vida cotidiana, pose, práctica social, textos, territorios, blogs, notas en la heladera, fashion" (154). Se cruzan los discursos sobre la literatura y se cuestiona a su vez esta suerte de literatura procesada. “¿Cómo oponerse a estos fragmentos de vida?” (155). La repetición y la construcción del yo están en el centro del escenario íntimo, operando como marca indeleble entre las borras del alcohol y los esbozos microcríticos. Por otra parte, hace referencia a $L a$ novela luminosa de Levrero:

Como nos tomaba el tiempo ese Levrero con su poética de farmacia. Qué reality más impresionante y sin usar más que palabras: todo ese detallismo proliferante de la vida cotidiana en torno a la preparación de la escritura -instalación de un aire acondicionado, compra de un sillón de leer y de novelas policiales en oferta, pasos contrafóbicos- y del mantenimiento de la fuerza de trabajo (el cuerpo) regulación 
entre combustibles farmacéuticos como antihipertensivos, antiácidos, café y aspirinas y naturistas como el yogur artesanal de factura propia, guisos y milanesas preparados por una ex amante- para que el "Diario de una beca" actúe como un subrayado por contraste a la experiencia narrada en La novela luminosa, donde la iluminación consiste precisamente en la trascendencia del cuerpo material a través de epifenómenos como la telepatía, la despedida póstuma y el sueño profético. 0 sea, es un efecto: ¡la vida misma es un efecto! (273).

29 En la cita se destaca esta obra que funciona como efecto, es decir, como montaje ficcional del yo: el escritor que pone el cuerpo para escribir, exhibe su intimidad, la comparte, la expone y de este modo, el discurso que "actúa" como parte de esa experiencia escrita. La intimidad, la adicción y la repetición, entonces, operan como mecanismos que construyen la compleja temporalidad y espacios de las formas de los discursos, mientras que la adicción se enmaraña con las estrategias de la construcción de la intimidad.

De La novela luminosa de Mario Levrero "leen la vida opaca. Es que Levrero recicla para la literatura lo que ella no se podría tragar" (271). La idea de reciclaje literario, coloca al fragmento en el meollo del cuestionamiento sobre el discurso contemporáneo y reafirma de alguna manera cómo operan esos segmentos dentro de una "poética de farmacia", adictiva, descriptiva, exhibicionista del yo, que a fin de cuentas caen en la repetición componiendo la temporalidad literaria.

\section{Movimientos del discurso: la adicción}

Las adicciones funcionan en las tres obras, conformando espacios de intimidad y marcando ciertos excesos en los procesos escriturales y en la transgresión. Si la repetición es el ritmo que va marcando los movimientos del discurso rioplatense cuyo espacio referencial es la intimidad, la adicción como movimiento también desplaza la escritura y la estanca, funciona como impulsora y como suspensión al mismo tiempo. Por eso, Moreno afirma que "si el olvidar es siempre una selección y edición de los recuerdos que oscilan entre los felices y los soportables, para el alcohólico gran parte de ellos pertenecen a la selección y memoria de los demás" (2016: 401). Así, las subjetividades que se exponen el acto de escritura, diagraman un montaje de la vida cotidiana y su exhibición que desde la soledad bosqueja las modulaciones del texte- , y surgen una serie de episodios en los cuales ciertas sustancias impulsan o traban la escritura; la movilizan y la fracturan, la impulsan y la truncan.

32 Como dijimos previamente, la problemática de los géneros literarios y del giro autobiográfico dan lugar a una reflexión sobre la intimidad y la repetición, pensadas como formas de la exhibición de lo íntimo. Por consiguiente, la aproximación a la noción de adicción tiene que ver con el movimiento del discurso, es decir con el espacio de la intimidad y con la ritmicidad que marca la repetición.

Al respecto, Suely Rolnik postula que nos encontramos en una suerte de toxicomanía generalizada causada por diversos tipos de drogas que causan el consumo de ilusiones (Rolnik 1997). En esta dirección, la autora propone que se mantiene cierto régimen identitario en la construcción de subjetividades que asimismo caracterizan formas de resistencia. La subjetividad se encuentra en:

[...] estado de falta permanente y promueve una verdadera toxicomanía de identidad, sustentada y producida por un variadísimo mercado de drogas. Romper con tal régimen identitario sería una condición esencial para que pueda afirmarse 
el inmenso potencial de creación en la existencia individual y colectiva, que es portadora a la actualidad (6) 5 .

Si el siglo XXI impone esta toxicomanía generalizada: ¿qué crea la adicción en el movimiento del discurso? ¿Por qué se repite en esa adicción? Quizás por qué no se puede postergar al goce; porque no se puede renunciar a la escritura. Lo que nos interesa aquí es el efecto en el proceso de escritura y de la construcción subjetiva. En este sentido, el exceso y la repetición en el discurso, vinculadas a las adicciones, se piensan como imposibilidad de renunciar al goce.

Por ende, la identidad del sujeto que enuncia está signada por el proceso hacia el devenir escritor. Resulta fundamental a este punto destacar que la adicción, a partir de una aproximación piscoanalítica, se concibe como una experiencia de goce, es decir, que presupone cierto placer mortífero y "curiosamente el instinto de muerte vale como principio positivo originario para la repetición: allí está su dominio y su sentido" (Deleuze 2002: 43). Esto se hace evidente en el El pasado cuando “...la condición del goce de la víctima es el verdugo (...) El artista es al mismo tiempo la mente que concibe la idea, la mano que la ejecuta y la materia que la sufre" (380). sujeto involuntario produce, apunta, anota, repite rutinas. La experiencia de la vida cotidiana y de la intimidad hacia las introspecciones de la muerte y de frustración como cuando dice explícitamente: "voy a sufrir. Ya estoy sufriendo" (266), conforman una suerte de ritmo depresivo que justamente no llevará a encontrar o a dilucidar los elementos luminosos de la "novela". Visto así, el goce en la adicción es indisociable de la pulsión de muerte ${ }^{6} \mathrm{y}$ la compulsión de la repetición, la transgresión y el exceso.

Emborracharse, en el caso de Moreno, también le da al discurso un movimiento, un impulso de poner en primer lugar esa adicción para enunciar desde esa imposibilidad de dejar el vicio, como tampoco se puede postergar el placer. El alcohol se presenta con total evidencia como la adicción de Moreno que su vez funciona, a modo de pasarela, colocando la repetición en el centro de la escritura. Crespi al respecto se interroga si en la neurosis que él identifica, el alcohol funciona realmente como adicción, dónde es que se percibe el punto de partida de la neurosis y dónde lleva, teniendo presente que en la literatura se plantea como imposibilidad de escritura (2017b: 3).

38 Los excesos que impiden que el proceso de escritura empiece o que promueve que se repita en la novela de Pauls invade el espacio de la traducción “...la cocaína en este contexto, le parecía una redundancia. La droga, la verdadera droga, era traducir: la verdadera sujeción, el anhelo, la promesa [...] Tal vez traducir había sido su escuela de droga" (106). Pauls dice que "La cocaína era autorreferencial: eliminaba todo lo que no era ella [...] la droga, en el caso de la cocaína, era la toma misma" (101). De este modo, la adicción que se manifiesta en tanto acto escritural, entre la esfera de la intimidad y la repetición, van conformando el espesor de la literatura, construyendo borradores o fragmentos de escritura que se retoman y se descartan.

Por otra parte, Moreno argumenta que el alcohol es una patria "por eso nunca se la pierde. Sólo se puede estar exiliado de ella" (2016: 258). Levrero alude al discurso vacío que relata la imposibilidad de escribir, haciendo hincapié en el hecho de que el problema no reside en el poder creativo, sino en la voluntad de devenir escritor "estoy cansado de representar ese papel" declara mientras se sumerge en búsquedas de programas para su adicción a la web, "Me he fascinado con los pequeños robots y sus alegres colores y su funcionamiento" (Levrero: 431). 
40 La vida se escapa en "la adicción absurda a la computadora", trascendiendo las posibilidades de vivir el proceso de creativo como una experiencia placentera, intelectual o ingeniosa, ya que "mi literatura era más importante que yo mismo". La literatura funciona como ente abarcativo, como desplazamiento del yo, como intrusa en la intimidad del escritor. Hay algo del mecanismo de la literatura que no se aliena con el sujeto que la escribe. En este intersticio se visualiza la repetición y la adicción que acechan permanentemente lo íntimo.

41 La computadora, el aparato, la tecnología, todo eso va ocupando un lugar en el diario de Levrero. La adicción reposa en la parte improductiva de la máquina: aquel objeto que nos ahorraría el tiempo con su empleo eficiente, no hace más que ejercer un poder devastador sobre la voluntad, un poder de coartar el acto creativo, de hacer del tiempo libre un salto al vacío. Disponer del tiempo es, ante la computadora, una tarea imposible. Levrero se ve sumergido por días, horas, o semanas en juegos virtuales, en la exploración de programas, consumo de pornografía, es decir, en un descontrol total del tiempo productivo de la escritura. Acerca del consumo ininterrumpido de los dispositivos tecnológicos, Graciela Montaldo realza la inserción de este comportamiento como una forma cultural de consumo. Ante la obsolescencia del tiempo, en esta práctica, este rasgo actúa como una especie de forma cultural por medio de la cual se traza un nexo comunicativo entre los objetos y lo material (2017: 109):

[...] estas adicciones que me perturban actualmente no son otra cosa que las adicciones al estado de trance; un medio de abreviar el tiempo, de que el tiempo pase sin que yo sienta dolor. Pero así también es como se me va la vida, cómo mi tiempo de vida se transforma en tiempo de nada, un tiempo cero (Levrero: 138).

Escribir es producir. Y si es así, para Levrero, ponerse a redactar su Diario es una lucha contra la improductividad, contra la hoja en blanco. El gasto inútil del tiempo se relaciona estrechamente con la pasividad frente a la computadora, al enorme tiempo invertido en el ocio.

43 Es posible identificar dos espacios que suelen trastocar el orden del discurso: el exterior y la computadora: "Un mundo cerrado o casi cerrado. La realidad virtual" (232). El exterior deja al personaje agotado, lo abruma, lo interrumpe. El espacio íntimo de la casa, se asocia inmediatamente con el momento del ocio, del desperdicio del tiempo, pero es un lugar de resguardo. La adicción marca el empezar de nuevo la escritura, mediante los espacios en blanco fuera de la pantalla, fuera del juego, del discurso dinámico improductivo.

La adicción lleva también a un exceso físico: al desborde, la autoflagelación, el deterioro. Esto se traduce, por ejemplo, en formas de sangrado: Rímini se masturba hasta sangrar y muere desangrado; a Levrero le sangra la nariz y Moreno sufre de hemorragias crónicas "La llegada de la sangre era impuntual. Me dolía tanto que solía quedarme en cama [...] Comencé a sufrir hemorragias" (Moreno 2016: 52). Pauls lee Black out, admitiendo en esos flujos (de la sangre, del alcohol) el movimiento de la creación textual:

45 María Moreno sabe que el alcohol ya fue y sangra por la herida. El nexo entre hemoglobina y botella la lleva incluso a fraguar una parodia del principio de Arquímedes: todo lo que le entra al cuerpo como alcohol le sale como sangre (2016). Intimidad y adicción aquí se interpelan con esa barra móvil entre adicción/intimidad, entre los movimientos del espacio y del yo, coloco la barra como elemento divisorio e 
integrador a la vez. En cambio, El pasado, Rímini es el centro, el intelectual que traduce y toma, que marca el impulso del discurso cuando el personaje:

[...] entraba en un territorio desierto, hacía que husmeaba, y se iba, y esa fugaz concesión del mundo de los hechos se le aparecía después, cuando se inclinaba sobre los libros y reanudaba su trabajo, como una distracción imperdonable. Hacía apenas una semana que había empezado a drogarse, pero ya la vida se le presentaba como una batalla sin matices. Sólo quería traducir. El resto- lavarse los dientes, comer, salir, hablar por teléfono, vestirse, ver gente, abrirle la puerta al fumigador eran obstáculos, interferencias, tentativas de sabotaje. En una semana, como si su encuentro con la droga no hubiera sido una novedad, el principio de algo, sino más bien la coronación de un proceso largo pero imperceptible (82).

Procesos y comienzos como producto de la droga y la droga como resultado de una escritura imparable. La literatura y la vida, entonces, como decía Laddaga, operan en la base de un laboratorio estético, de un trabajo con el lenguaje y con las formas literarias de escribir la temporalidad. La experiencia vivida y sentida, se coloca en el centro de la novela: "Los días, la cocaína, las horas absortas en las traducciones y las visitas de Vera hicieron el resto. La extirpación, al principio brutal, no tardó en hacerse cotidiana" (96). La dificultad de la escritura se vive con la traducción, y Rímini se coloca en escena a partir de los focos de sus experiencias y fracasos en la vida amorosa, matizados con la sensación de la droga y las pulsiones mixturadas.

El tiempo se obtura junto con la obsesión amorosa; en este sentido el espacio y los tiempos del amor se repiten y están siempre en un punto inicial que parece no poder salir del pasado. Es la experiencia que retorna transformada como recurrencia, el recuerdo, la imposibilidad de renunciar a la cocaína, de declinar el goce:

La inercia no produce cambios. No produce nada, en realidad. A lo sumo da lugar a la degradación, por ejemplo, o a la entropía . El cambio sí: el cambio produce cosasinercia, por decir algo . Ahora bien, ¿quién se animaría a afirmar que la diferencia entre lo que cambia y lo que se degrada, entre una señal de alteración y otra de deterioro, es una diferencia real? (432).

En la maquinaria de Pauls, estos movimientos del discurso se repiten porque anular el pasado implica desafiar las leyes y límites de la percepción de lo real en el tiempo. Particularmente, lo íntimo, la repetición y la adicción se congregan, de a momentos en discursos entre los movimientos y el ritmo, funcionando en un proceso de acumulación que hace el espesor literario de la historia del pasado. Las expresiones corporales, dan cuenta de este conglomerado en las cuales se percibe el exceso a partir, por ejemplo, de la sangre que emana como elemento representativo del dolor físico, se identifica como una auto-provocación, como parte de la incontrolable adicción traducida en esto:

Rímini había podido formarse una idea bastante concreta de la acción propiamente química que la droga ejercía en su cuerpo, y también de su carácter paradójico: por un lado, hiperactividad, reservas inagotables de energía, máxima concentración, voluntad de extenuar las posibilidades del presente; por otro, anestesia, quita desafección, supresión de sensibilidad. [...] Traducía y tomaba, traducía y tomaba (103).

Asimismo, la traducción funciona como ejemplo de una labor continua, a veces marcada por los movimientos discursos que se acompañada con el consumo de droga, con los movimientos del cuerpo "la figura del traductor, situada en principio en el umbral de la escritura literaria, también se hace cargo de un imaginario que concierne en primer término al artista" (Orecchia 2013: 24). Es posible leer el entramado opaco del discurso temporal contemporáneo en la novela desde la mirada que plantea el movimiento del 
discurso marcado por la droga produce la fluidez del movimiento mental, mientras que la repetición en cuanto tiempo, retorna al pasado amoroso, al recuerdo, a la imposibilidad del cambio. El yo de Rímini invade la novela, asfixia la voz narradora, lo estremece de fracaso en poder seguir adelante con la historia sin que el fragmento amoroso retumbe en el centro del motor de cambio.

51 En este sentido, la adicción se construye en el entramado de las obras y en el deseo de producción escritural, mediado, estimulado o truncado por el objeto mismo de adicción.

\section{Conclusiones}

Contextualizar la literatura en lo contemporáneo vinculada a un tipo de escritura sería una tarea devastadora. Lo que notamos hasta aquí, es que las obras se conectan con lo emergente, con los márgenes y los cánones de la tradición literaria rioplatense. En estos textos que analizamos, en la repetición de la escritura, en la adicción alcohólica, a las drogas o al consumo tecnológico y las configuraciones de lo íntimo, se gira en torno a la experiencia de vivir el proceso de escritura y/o de narrarlo, trastocando los límites genéricos y las formas de la subjetividad.

Al hablar de adicción, repetición e intimidad, se percibe que en estas manifestaciones hay como una suerte de elemento limitativo y a su vez complementario, es decir, una frontera movible, una línea visible de unión y de interposición que palpita en el proceso de escritura. En esta suerte de contraste, lo íntimo se integra y se separa de la adicción, conformándose un lugar de enunciación a partir de la corporeización de la subjetividad que pone en juego la escritura como foco de atención. Es en la construcción de la subjetividad donde, sugiero, interfieren ritmos y movimientos discursivos que marcan los desbordes de las adicciones en el proceso de escritura.

Como notamos, se identifican transposiciones en los procesos de escritura y las voces que construyen a los sujetos de enunciación, obteniendo el resultado de obras colosales de cientos de páginas que convergen en un experimento de lo extremo. Extremo trabajado desde el acto de fragmentar en múltiples desplazamientos el tiempo presente de la escritura. En este sentido, es notable en la configuración del pasado que se entrevé en la lectura: todo lo que han leído, se conserva como parte de una memoria experimentada, como una prueba del potencial creativo. Si el pasado se escribió, ¿cómo salir de este círculo de pasarelas y pasajes, de esta nomenclatura que marca la vida cotidiana? Hubo, en la historia literaria expuesta en estas obras, un pasado de escritores que levantaron enormes bibliotecas, y en ese pasado, desde el presente, se puede solo contemplar por que la escritura no tiene historia. Es la intimidad la que se trastoca en esta cotidianidad de rupturas, en la adicción que se entromete en el fluir escritural. En el futuro no hay novela, no hay porque es un proyecto. Porque la vida que vuelve al pasado no puede con la lectura. Literatura y vida, se juntan y así, la vida con su banal ritmo de la cotidianeidad, nos retrae de ese pasado literario.

En cuanto al gesto confesional, en los movimientos y ritmos del discurso repetitivos, fragmentados, yoicos, Laddaga disputa sobre las maneras que existen de hablar de sí mismo. En la literatura en particular, aclara que es notable el tono de confesión en el cual se dirigen la mayoría de los autores contemporáneos o, al menos, lo frecuente que esto sucede cuando "un escritor habla en nombre propio, describe la circunstancia, en 
el mismo lugar, la misma página, o el mismo libro, en que despliega fabulaciones a veces extremas, de modo que a nosotros, sus lectores, podría parecernos que no distingue entre una cosa y otra" (2010: 29).

Las maneras de hablar de sí mismo, teniendo en cuenta las distintas disposiciones del sujeto de enunciación, van configurando una intimidad que se expone ante el lector, que dialoga con éste. En este sentido, la confesión "sería tanto un acto de exploración no ajeno al pudor y al desprendimiento como uno de restricción de las tentaciones del yo por completarse bajo el cobijo de un nombre propio indiscreto en los detalles de su personalidad" (Moreno 2008).

En relación con la adicción, la intimidad va componiendo una zona compleja de fijeza y dinamismo entre los ritmos de la repetición y los movimientos de la adicción. En Levrero, se genera el vicio ante la pantalla y la rutina marcada por esta inmersión y el estatismo que se imponen como motor de construcción de lo íntimo; en Moreno transitamos los fragmentos de lo íntimo entre el alcohol, el vino, el cuerpo borracho, las lecturas y la erudición volcada en versión de microcrítica en Pauls, Rímini palpita con la adrenalina de los encuentros y los reencuentros amorosos, consumados y consumidos por la cocaína, entre las líneas de palabras por traducir.

En las reflexiones finales, a partir del recorrido propuesto, dejo abiertas las posibilidades para pensar algunos mecanismos y operaciones que tejen el discurso contemporáneo con sus fragmentos y sus repeticiones, con sus despliegues de experiencia, con las adicciones y con la intimidad exhibida. Estos discursos se piensan tanto en los modos de vida contemporáneos representados como en aquellos ligados al proceso de la escritura y la experiencia volcada en ésta, como formas de expresión de lo íntimo a través de la exposición plena la subjetividad. En sintonía con lo dicho, refiriéndose a la publicación de una novela de Pauls, Moreno dice respecto a la experiencia:

La vida artística como una manera de replantear la vieja dicotomía entre arte y vida. La literatura expandida como una forma de repensar los géneros, las fronteras y los clichés de la literatura autobiográfica. El tiempo del periodismo, las antologías y los artículos por encargo y el tiempo de la literatura (2012).

Más allá de pensar que pueda identificarse una literatura expandida, autobiográfica o no, se entiende esta postura, como un armado de un escenario ficcional en el cual la vida se expone, narrándose la experiencia que imposibilita o limita la misma ficción fuera de lo subjetivo. Literatura y vida como formas de la postexperiencia que franquean una escritura postergada $\Leftrightarrow$ como dice Premat, inacabada, plagada de barreras en el proceso creativo.

\section{BIBLIOGRAPHY}

Astutti Adriana, "Ejercicios de caligrafía: Mario Levrero", BOLETIN/13-14 del Centro de Estudios de Teoría y Crítica Literaria, Rosario, (Diciembre 2007 - Abril 2008), Web. Consultado el 1/4/2019. 
Crespi Maximiliano (2017a), "La sed verdadera (9 notas sobre Black out de María Moreno)", Cuadernos LIRICO, 17, 2017, Web. Consultado el 1/4/2019.

--- (2017b), Black out, Chuy. Revista de estudios literarios latinoamericanos 4, Diciembre 2017, p. 93-106.

Deleuze Gilles, Diferencia y repetición, Buenos Aires, Amorrurtu editores, 2002.

Giordano Alberto (2007), “Cultura de la intimidad y giro autobiográfico en la literatura argentina actual”, Pensamiento de los confines, № 21, Diciembre 2007, Web. Consultado el 1/04/19.

--- (2008), El giro autobiográfico de la literatura argentina actual, Buenos Aires, Mansalva.

--- (2017), "Notas sobre diarios de escritores", ALEA, vol. 19/3, Rio de Janeiro, Septiembre-

Diciembre, p. 703-713.

Laddaga Reinaldo (2007), Espectáculos de realidad, Rosario, Beatriz Viterbo Editora.

--- (2010), Estética de laboratorio, Buenos Aires, Adriana Hidalgo.

Laplanche Jean y Jean-Bertrand Pontalis, Diccionario de psicoanálisis, Buenos Aires, Paidós, 2004.

Levrero Mario, La novela luminosa, Buenos Aires, Random House, 2016.

Montaldo Graciela, "Obsolencia y escritura. La sobrevida de las cosas en la política del tiempo", en Carlos Walker (ed.), Mil hojas. Formas contemporáneas de literatura, Santiago de Chile, Hueders, 2018, p. 107-126.

Moreno María (2016), Black out, Buenos Aires, Random House.

--- (2013), Subrayados. Leer hasta que la muerte nos separe, Buenos Aires, Mardulce.

--- (2012), “Artevida: ese vintage”, Radar Página 12, 30 de septiembre, Web. Consultado el $1 / 4 / 2019$.

--- (2011), “La mujer invisible” (entrevista por Violeta Gorodischer), Radar. Página/12, 22 de junio, Web. Consultado el 1/4/2019.

--- (2008), "Yorando en el espejo", Radar Libros, Página/12, 27 de enero, Web. Consultado el $1 / 4 / 2019$.

Orecchia Havas Teresa, “Apuntes sobre el territorio y la creación: vidas de Alan Pauls”, Cuadernos LIRICO, 9 | 2013, Web. Consultado el 1/4/2019.

Rolnik Suely, "Toxicômanos de identidade. Subjetividade em tempo de globalização", Daniel Lins (org.), Cultura e subjetividade. Saberes Nômades, Web. Consultado el 1/4/2019.

Pardo Carlos, "El alcohol es una patria”, Babelia EL PAÍs, 11 de diciembre 2017, Web. Consultado el $1 / 4 / 2019$.

Pauls Alan (2003), El pasado, Anagrama, Buenos Aires.

--- (2016), “El libro de la semana por Alan Pauls: Black out de María Moreno”, CRÍTICA, Buenos Aires, 23 de diciembre, Web. Consultado el 1/4/2019.

Premat Julio (2016), “Las puertas de Levrero”, Cuadernos LIRICO, 14, Web. Consultado el 1/4/19.

--- (2018), Non nova sed nove. Inactualidades, anacronismos, resistencias en la literatura contemporánea, Roma, Quodlibet. 


\section{NOTES}

1. Es interesante relacionar esto con la noción de extrême contemporain estudiada en la literatura francesa contemporánea, ya que añade un elemento para especular en torno a la estética del fragmento y la repetición. Desde este punto de vista, el fragmento a su vez coloca en el meollo de la discusión del término de lo extremo.

2. Adriana Astutti alude a estos mecanismos como "instrucciones de uso" dentro de la "terapia grafológica" de Levrero. En este sentido, escribir garantiza un valor literario.

3. Respecto a esto Carlos Pardo agrega que: "También porque es un testamento y, a la vez, una obra primeriza que inaugura posibilidades en un género que los cazadores de tendencias llaman autoficción, etiqueta que también se queda corta en este caso" (2007).

4. La novela luminosa de Levrero sustenta su escritura mediante varias citas, por ejemplo, el día 06/09/2000 para dar cuenta de la falta de voluntad que de alguna manera no estimula el proceso de escritura de la novela, Maughan es el referente de esta teoría con su libro Lo mismo de siempre (The mixture as before): "la voluntad necesita obstáculos para ejercitar su fuerza" (105), se coloca la palabra esfuerzo en primer plano resaltando que para escribir se requiere de esfuerzo y para esto, tiene que haber un motor que propulsa tal energía.

5. Cita original en portugués (la traducción es mía): "estado de falta permanente e promove uma verdadeira toxicomania de identidade, sustentada e produzida por um variadíssimo mercado de drogas. Romper com tal regime identitário seria uma condição essencial para que possa afirmarse o imenso potencial de criação na existência individual e coletiva, de que é portadora a atualidade".

6. "El instinto de muerte no aparece vinculado con las tendencias destructivas ni con la agresividad, sino en función de un examen directo de los fenómenos de repetición" (Deleuze 200: 43)

\section{ABSTRACTS}

The aim of this article is to study the contemporary literature based in Rio de la Plata: Black out (2016) from María Moreno, El pasado (2004) from Alan Pauls and La novela luminosa (2005) from Mario Levrero. The purpose of the article is to identify a double movement and a rhythmicity present in the discurse: firstly, the movement of intimacy, which puts the subject of enunciation in the centre: its life, its daily life, its organic functioning, its corporality, its physiological feeling, etc., secondly, the repetition is conceived as a rhythm, as a return from the point of view of temporality, fragmentation and fluency; finally, the article will study the addiction's movement, meaning it in terms of repetition and excess, of pleasure and frustration related with the writing process. This article explains the issues related with the writing process taking in account two aspects linked with the mentioned elements: one is connected with the problem of undefined literary genders, and the other is linked with the autobiographical turn.

Este artículo se centra en un corpus de obras contemporáneas: Black out (2016) de María Moreno, El pasado (2004) de Alan Pauls y La novela luminosa (2005) de Mario Levrero. Se parte de la premisa que contempla un doble movimiento y una ritmicidad del discurso: el movimiento de lo íntimo, 
que pone al sujeto de enunciación en el centro: su vida, su cotidianeidad, su funcionamiento orgánico, la corporalidad, el sentir fisiológico, etc.; en segundo lugar la repetición es concebida en tanto ritmo del discurso, como retorno, desde un punto que acecha la temporalidad, la fragmentación y la fluidez; por último, estudiamos el movimiento de la adicción, en tanto elemento de repetición y exceso, de goce y de frustración en relación con la escritura. En torno al proceso de escritura y estos elementos, se cuestionan dos aspectos: los géneros literarios y sus manifestaciones indefinidas y el estatuto del sujeto de enunciación pensando en el giro autobiográfico.

Cet article est centré dans un corpus d'œuvres contemporaines: Black out (2016) de María Moreno, El pasado (2004) d'Alan Pauls et La novela luminosa (2005) de Mario Levrero. On part du principe qu 'envisage un double mouvement et à une cadence du discours : le mouvement de l'intime qui place le sujet d'énonciation, sa vie, son quotidien, son fonctionnement organique, sa corporalité, son ressenti physiologique, etc. ; la répétition, en tant que rythme, en tant que retour, d'un point qui concerne la temporalité, la fragmentation et la fluidité ; enfin, le mouvement de l'addiction, en tant qu'élément de répétition et d'excès, de jouissance et de frustration en relation avec 1 'écriture. Autour du procès d'écriture, il y a deux aspects qui seront mis en cause : les genres littéraires et leurs manifestations indéfinies et le statut du sujet de l'énonciation en pensant au tour autobiographique.

\section{INDEX}

Palabras claves: adicción, intimidad, repetición, literatura contemporánea, subjetividad Keywords: addiction, intimacy, repetition, contemporary literature, subjectivity

Mots-clés: addiction, intimité, répétition, excès, littérature contemporaine, subjectivité

\section{AUTHOR}

\section{LUCÍA CAMINADA ROSSETTI}

Universidad Nacional del Nordeste, UNNE/ IIGHI -CONICET

lucia.caminada@gmail.com 